Short-term outcomes of communication aid provision

\title{
M.T. Clarke,
}

Developmental Science, Psychology and Language Sciences, University College London

C. Newton,

Developmental Science, Psychology and Language Sciences, University College London

\section{J. Cherguit}

Developmental Science, Psychology and Language Sciences, University College London

\section{Donlan}

Developmental Science, Psychology and Language Sciences, University College London

\section{J. A. Wright}

Health and Life Sciences, De Montfort University

Corresponding author:

Dr Michael Clarke

Developmental Science,

Psychology and Language Sciences

Chandler House

2 Wakefield Street

London, WC1N 1PF

m.clarke@ucl.ac.uk

Acknowledgements:

The authors would like to thank the children who agreed to take part in this study. The research was funded by a grant from the Department of Education (formally the Department for Education and Skills). 


\begin{abstract}
The aim of this study was to explore the short term outcomes of communication aid provision. Ten children were interviewed at two time points. First interviews took place before or within two weeks of the arrival of a new communication aid. A second follow-up interview was carried out between six to ten weeks later. Initial interviews explored children's views concerning their ability to engage in school activities that they deemed important but difficult to achieve. First interviews also examined children's self-perceptions related to their self-efficacy and self-esteem, and perceptions of others' attitudes towards them. Children's views on the likely impact of the new communication aid on taking part in activities and their self-concepts were also explored. The follow-up interviews asked children to reflect on the short term impact of the new communication aid. Children reported expected and unexpected positive changes at follow-up. Notably, unanticipated and undesirable changes were also reported.
\end{abstract}

Keywords: Augmentative and alternative communication, children, outcomes, interviews 


\section{Introduction}

The provision of new augmentative and alternative communication (AAC) technology to children with communication difficulties brings with it numerous opportunities and challenges for the children themselves, their families and the professionals who support them. Child and family anticipation of, and early response to, the introduction of AAC will affect short-term outcomes and mould the context of longer-term impact (Fuhrer, Jutai, Scherer \& DeRuyter, 2003; Lenker \& Paquet, 2004). Establishing expectations and early experiences of AAC provision is therefore an important area of focus for practitioners and researchers, and salient insights may be gained by exploring children's subjective experiences at the early stages of new AAC provision. An aspiration to capture children's accounts, including those who have learning and communication disabilities, on issues that concern them has received considerable attention within education, social services and health service policy and guidance in England. Policy initiatives have been accompanied by developments in guidance for designing and conducting research and clinical work aimed at establishing children's perspectives (e.g. Lewis \& Porter, 2004), and exploring the views and experiences of children and young people with disabilities has been a growing focus of research activity for a number of years (Cavet \& Sloper, 2004; Rabiee, Sloper, \& Beresford, 2005b) (Wickenden, 2010). Research practice in the field of AAC has mostly been concerned with the reported experiences of adults provided with AAC. Such work includes adults' reflections on the use of communication aids (Rackensperger, Krezman, McNaughton, Williams, \& D'Silva, 2005; Smith \& Connolly, 2008), service provision (Brewster, 2004; Hodge, 2004; Lund \& Light, 2007), use of leisure services (Dattilo et al., 2008) and priorities for research (O'Keefe, Kozak, \& Schuller, 2007). Where research has been carried out with children and young people with little or no functional speech, it has examined issues such as those related to service provision (Clarke, McConachie, Price, \& Wood, 2001), aspirations and desired outcomes (Beresford, Tozer, Rabiee, \& Sloper, 2007; Rabiee, Sloper, \& Beresford, 2005a), aspects of communication aid use (Hodge, 2007; Morris, 2003), and identity (Wickenden In Press). Thus researchers and interventionists in education, social and health services have been provided with insights into social, cultural, service-related and attitudinal factors that may directly or indirectly influence outcomes of AAC provision as judged by users of AAC themselves.

Over the past decade, intervention and evaluation strategy in the introduction and support of AAC for children has been increasingly influenced by the International Classification of Functioning, Disability and Health, (ICF; 2001) and more recently the version for children and youth (ICF-CY; 2007). The ICF-CY offers a framework for designing and evaluating intervention, encompassing child (body structures and functions) and contextual (personal and environmental) factors, and features of child and family activity/participation (e.g. see Griffiths et al. this edition). Conceptual models of assistive technology outcomes commonly promote a need to recognise the multi-faceted nature of outcomes, including for instance changes in psychological functioning and activities/participation, and the impact of contextual features on outcomes (see Lenker \& Paquet, 2003 for review of models). For example, Fuhrer et al.’s (2003) framework for conceptual modelling of assistive technology outcomes incorporates psychological functions (conation, affect and cognition), subjective well-being and activities/participation (in ICF terms) as key 
outcome variables of AT provision. Within the ICF-CY, activity is defined as the "execution of a task or action by the individual" (p.12) and participation as "involvement in a life situation" (p.12). While the short-term aims of AAC interventions with children will vary according to individual circumstances, developing skills in performing activities (e.g. expressive language use) is a common intervention target (Raghavendra, Bornman, Granlund, \& Bjorck-Akesson, 2007). Participation goals in ICF-CY terms are perhaps less easily identified and less frequently targeted (Iacono, 2003). Participation may be described as a multi-dimensional profile of features including for instance the range, type, frequency and context of pursuits carried out by the child (e.g. King, Law, Hurley, Petrenchik, \& Schwellnus, 2010). It has been proposed also that participation may be conceptualised and assessed in terms of the individual's personal sense of involvement, where involvement may be characterised as being engaged and being accepted (Granlund et al., 2011; World Health Org, 2001).

An increasing variety of AAC options is being offered to a growing range of children with communication difficulties. Despite the theoretical and practical significance of gaining insight into the short-term outcomes of AAC provision, and the relevance of seeking children's views concerning matters of import to them, there appears a paucity of research examining the early outcomes of AAC provision from the perspective of children themselves. The study reported here sought to explore children's views concerning the short-term impact of a newly-provided communication aid on their ability to perform activities in school and their subjective experience of involvement ((being engaged, being accepted)). Ability to perform activities was examined by investigating children's opinions about changes in the level of difficulty in carrying out certain communication-focused activities that were deemed important to them. The impact of the communication aid on the subjective experience of involvement was explored via children's changing perceptions of selfefficacy, self-esteem, and perceptions of others' attitudes towards them (Eriksson \& Granlund, 2004) following the provision of a new communication aid. Here short-term is taken to mean six to ten weeks following provision of the communication aid.

\section{Method \\ Design}

Interviews were conducted with children before or within two weeks of receiving a new communication aid (T1), and six to ten weeks following (T2) the provision of the new communication aid.

\section{Participants}

A convenience sample of 10 children due to receive voice output communication aid technology was recruited (Wright et al., 2004). Children were selected on the basis that their reported skills in 
understanding language would support full access to the demands of the interview, including reflecting on past events. Table 1 shows the profile of the children included in the interview study.

Insert table 1 about here

\section{Interview measure}

The core logistic principles for organising the research were that the interviews should minimise disruption to children's schools, and inform the research project quickly and reliably using repeated measures. The interview procedure was therefore designed to balance the practical and resource constraints of the study with the desire to engage children in sharing their views. Ethical review of the study protocol was undertaken, and approval was given for all procedures.

All interviews with children were based on the principles that established confidentially between the interviewer and the child, informed the child that the interviewer would keep some notes, established that there were no right or wrong answers, and demonstrated to the child how they could control the interview procedure including how they could stop the interview at any time, decline to answer a particular question, inform the interviewer that they didn't have an opinion or didn't want to answer, or that they didn't understand the question (Beresford, 1997).

The interview was developed from visual symbol-based procedures for interviewing adults and children who have little or no functional speech (Clarke, 2002; Clarke et al., 2001; Murphy, Gray, van Achterberg, Wyke, \& Cox, 2010; Weller, 2001). It centred on the organisation of symbol/picture representations of key issues under discussion, which were presented on a monitor using computer software designed by the research team. The procedure was designed such that any child could complete the interview using simple pointing gestures, including preferential looking, eye pointing, and without being required to speak. Thus, the interviewer and child worked together with materials presented by the computer in a 'triadic' framework of interaction. Arguably, this provided scope for the adult to support the interviewees' understanding and decision-making in response to computer-generated topics and questions. It was hypothesised that a triadic framework of interaction might also mitigate somewhat the degree to which the child viewed the adult as representing a particular point of view, and the child thus presenting responses that they perceived to be socially competent or desired by the adult.

\section{Time 1 procedure}


First, all children were presented with a laminated card on which the following discourse functions were represented: want to stop; don't understand; don't want to say; don't know; that's not what I meant. This card was available to the children throughout the interview with the aim of providing a mechanism with which children might signal the emergence of problems such as misunderstandings.

The T1 interview explored the children's experiences of a range of activities which typically take place throughout the school day, and how the provision of a communication aid might impact on the child's ability to carry out these activities.

The T1 procedure followed six successive stages, described below:

Stage 1: The children were first asked to identify a maximum of eight activities from an array of twelve, represented in symbol form. These activities, such as answering questions when you know the answer, and taking part in group discussions, were linked broadly with the ICF-CY communication categories of receiving messages, producing messages, and conversation. In seeking to represent visually key issues under discussion in an agreed composite picture, the procedure aimed to support young people in thinking about and reporting their views with some authenticity, and to provide an opportunity to assess the reliability of children's responses through the introduction of bogus issues / non-relevant events. If an activity was recognised by the children as relevant to their experience in school it was moved across the computer screen and located within a picture representing the child's school. Figure 1 shows the representation of school and schoolbased issues used in the interview.

\section{Insert figure 1 about here}

Stage 2: The children ten rated the activities selected as easy or difficult to carry out. Each child was presented with a horizontal line presenting the adjectives 'easy' and 'difficult' at opposite poles, and a mid way point indicating 'in between'. Children responded by showing where on the line they wished to put the symbol representing each activity.

Stage 3: The child was then asked to re-consider each activity to decide on how important it was to achieve. This decision was also supported by the presentation of a further horizontal line with opposing poles presenting 'important', 'not important' and a mid-way point indicating 'in between'. 
Stage 4: A summary of the child's decision-making was then presented and the child was asked to choose a single activity that was both 'difficult' and 'important' to discuss in greater detail. Where a child may not have identified an activity as both 'difficult' and 'important', one 'difficult' item was chosen by them to be taken forward.

Stage 5: Having identified a difficult and important activity, the child was presented with a series of statements representing issues related to: (i) self-efficacy, (ii) self-esteem, and (iii) perceptions of others' attitudes. Each statement was portrayed in symbol form, and the child was asked to consider whether or not it matched, or was similar to, their own experience in the context of performing the important and difficult activity and/or joining in with school life generally. Table 2 lists each issue.

\section{Insert table 2 about here}

Stage 6: In this stage of the procedure the child was asked to indicate the relative strength of opinion associated with each self-efficacy, self-esteem, and others' attitudes statements they had identified as reflecting their own experience. This aspect of the procedure was modelled using the reported experiences of other children. The other children were represented by three child characters illustrated as child faces, illustrated in figure 2 (Clarke et al. 2001; Weller 2001; see also Rabiee et al 2005b). Each character in turn was then shown to rate the statement as a big problem, one as not a big problem, and the third as somewhere in between. The association of character to level of problem was varied for each statement. The child was then asked to indicate their own view by locating the symbol on 'big problem' to 'small problem' scale.

\section{Insert figure 2 about here}

\section{Time 2 procedure}

The activities rated both as difficult and important in the first interview were revisited in the T2 interview in which the participants again rated the importance of these activities and stated whether they had become easier, more difficult or stayed the same. Items examined in stage six of the T1 interview (self-efficacy, self-esteem, and others' attitudes statements) were also reviewed and children asked to consider whether their views had changed since the provision of the communication aid. 


\section{Procedures}

Pilot testing of the interview procedure was conducted with two typically-developing children and four young adults with physical disabilities using VOCAs. Consent to participation in the research was first sought from parents/carers before approaching the children. The children were provided with symbol-supported information which described the aims of the study, its outcome, and the children's role in the work. Information sheets were given to the children which set out the principles of right to dissent from participation and withdrawal from the study at any time following assent. The participants' anonymity in project reporting was highlighted, and if interviewees chose not to share the outcomes of the interview with others in school or at home, they were informed that the findings would remain confidential. Children's interviews were conducted at their schools, and the children able to decide whether or not they wished to be accompanied by a member of staff.

\section{Findings of the study}

First, a summary of findings from across the group of ten children is presented. This is followed by an illustrative case study. In order to maintain the children's anonymity all names have been changed.

\section{Group findings}

\section{Activities}

At $\mathrm{T} 1$, children were asked to identify a maximum of eight activities from an array of 12 , that were relevant to their experience of school life. Activities selected across the group were: cooking, playing (with objects), reading (including news articles), sports, joking, asking questions, expressing alternative views (disagreeing), telling news, talking in front of class, answering questions when you know the answer, talking in groups, listening to the teacher. All children in the group selected answering questions when you know the answer, talking in groups and listening to the teacher.

\section{Important and difficult activities}

The children identified six activities out of a possible 12 activities as both important and yet difficult to achieve: asking questions, answering questions when you know the answer, telling news, joking, talking in front of the class and talking in groups. Talking in front of the class, and talking in groups were most frequently selected with three and four children, respectively, highlighting these activities. 


\section{Predicted changes and experiences}

Children's predictions varied concerning the change in level of difficulty they might experience in engaging in a number of activities (see figure 3). Most notably perhaps, a majority of children anticipated that asking questions and talking in groups would become easier following the provision of the communication aid. More balanced views were expressed in relation to telling news and talking in front of class. Level of difficulty in joking and answering questions was viewed by most as unlikely to change following the provision of the communication aid.

\section{Insert figure 3 about here}

\section{Changes in difficulty}

The children reported changes in the degree of difficulty experienced in participating in the difficult and important activities following new communication aid provision. Talking in groups was most positively affected by the new aid. For half the children interviewed, telling news became more difficult. Answering questions when the answer is known provoked the most mixed responses with the activity becoming easier for some children and more difficult for others at $\mathrm{T} 2$.

\section{Changes in factors related to self-efficacy, self-esteem and others' attitudes factors}

Overall, a general reduction was observed in the degree to which issues related to self-efficacy and self-esteem were problematic. For many children there was a noted reduction in the amount of effort exerted in communication, feelings of embarrassment and frustration, and in the perception that other people think the communication aid user cannot help them (see figure 4).

\section{Insert figure 4 about here}

\section{Case study}

Maya was 14 years old at the time of her interview. She has cerebral palsy and experiences significant difficulties generating functional speech. She has great difficulty walking and uses a wheelchair. Maya's assessment for a new aid was initiated because at the time her current simple communication aid did not provide suitable functionality to support and develop her communication 
potential. Suitable mounting equipment was also provided to secure the device to her wheelchair and position it in a way that she can access it with greatest efficiency. At the time of the interview Maya attended a special school for children with physical disabilities.

Maya identified six events that reflected her everyday activities in school. Her views concerning the relative difficulty of these activities, and how important she felt they were to her, are presented in table 3.

\section{Insert table 3 about here}

Maya gave a range of opinions concerning these activities. She identified joking / teasing as something that was easy and was rated as neutral in terms of its importance. She did not expect this to change over time. The activities she found most difficult were 'telling news' and 'talking in groups'. She indicated that telling news was not particularly important for her but that talking in groups was important, and it was this activity that was chosen to discuss in more detail.

When presented with a range of statements and asked to consider their relevance to her own experience in the context of talking in groups, Maya identified 11 issues. Although a number of factors associated with self-efficacy were identified as relevant problems, these were rated as less significant difficulties than factors associated more directly with self-esteem, including feelings of not having a voice, and feelings of frustration and embarrassment.

At the T2 interview she identified no change in the level of difficulty in answering questions, talking in front of the class and telling news, and this matched her expectations for change in the short term. Interestingly, she perceived the ability to ask questions, an activity identified as an important one to her, had become more difficult in the intervening period. However, she reported an unexpected increase in her ability to joke and tease with others. She also reported improvements in her ability to talk in groups, an activity she had identified as difficult but one that was important.

When asked to look again at the statements about self-efficacy, self-esteem and others' attitudes, no change was reported in relation to eight items (see table 4). For example, Maya reported similar levels of frustration at the time of the second interview. However, she indicated a reduction in the 
problems of other people talking for her and other people thinking she had nothing to say. Significantly, she also reported a reduction in the issues she previously rated as big problems including being treated as stupid and feelings of embarrassment.

\section{Insert table 4 about here}

\section{Discussion}

The aim of this study was to examine short-term outcomes of AAC provision by exploring the views of children receiving new communication aids. Interviews with children were first conducted before or within the first two weeks of receiving a new communication aid, and then between six and ten weeks later. Interviews investigated children's expectations for, and later their reflections on, the impact of the communication aid on their ability to perform communication-focused activities, and their self-perceptions relating to self-efficacy, self-esteem and others' attitudes towards themselves. Children's self-perceptions were explored in the context of carrying out activities that they identified as difficult to achieve but important to them, and in relation to participation in school more generally.

Children reported changes in the level of difficulty in performing a range of communicationfocused activities in school. While for some, a reduction in the level of difficulty experienced was reported, others reported no change, or an increase in difficulty. Where positive changes are observed in the short term, this would seem particularly encouraging bearing in mind that the second interviews took place in some cases as little as six weeks after the children were introduced to their new communication aids. For some children, communication aid provision would seem to have an early positive impact. This study also draws attention to unanticipated positive outcomes of communication aid provision. For example, Maya's case study illustrates that the communication aid provision contributed to unforeseen gains in the ability to joke with others.

For some of the children in this study, expectations for how the level of difficulty may change in carrying out activities did not match their experience at the time of the second interview. The fact that for some children in the early weeks following provision of an aid, their accomplishment of some activities was proving more problematic and did not meet their expectations is an important observation. In the short term, it is possible that new communication technologies introduce new, perhaps unforeseen, barriers to interaction. Explicit acknowledgment of the demands on children and others of learning new communication aid technologies is highlighted (Drager, Light, Speltz, Fallon, \& Jeffries, 2003; Murray \& Goldbart, 2009). For example, learning the fundamental 
operating requirements, combined with developing knowledge and skills in the effective deployment of communication aid mediated contributions (Light, 1989), will require considerable effort by children themselves and those that support and care for them. Such findings also point to and reinforce the need for careful planning of early intervention goals with children and families, and the management of child and family expectations as a primary focus of professionals' support to children receiving communication aids (see also, for example, Newton et al., 2007).

The children in this study generally reported a reduction in the degree to which they rated as problematic issues associated with participation involvement: self-efficacy, self-esteem, and others' attitudes. While the exploration of such issues was limited, these children's self-perceptions reveal positive outcomes that may not be reflected in observable practices such as asking questions. Parent and child counselling concerning children's shifting self-perceptions with the introduction of new communication aids would appear a credible area of exploration for practitioners and researchers.

Augmentative and alternative communication interventions may lead to expected or unexpected outcomes that may be advantageous or undesired, and the timescale over which change may be reasonably measured will vary with child, family and environmental contexts and type of intervention goal (Granlund, Bjorck-Akesson, Wilder, \& Ylven, 2008). Those seeking to determine the impact of communication aid provision are likely to benefit from establishing as routine practice a profile of outcomes incorporating activity and participation domains assessed through objective measurement and subjective perspective. Arguably, the processes and outputs of such work are likely to prove valuable to children and families as well as professionals. For practitioners, developing holistic and individualised profiles of goal setting and outcomes across time, that incorporate the view of children as well as families, may also contribute usefully to evidence of professional accountability.

It is recognised that outcomes of communication aid provision are influenced by multiple child and environmental variables. For example, for children using communication aids, child personality (emotional intelligence) and family impact of childhood disability have been highlighted as possible predictors of outcome in terms of child and family participation (Clarke et al., 2011). Conceptual models of assistive technology outcomes seek to reflect such multiplicity (Lenker and Paqet, 2003), and work examining children's own views concerning the use of assistive communication technologies can provide empirical support for the development and refinement of the theoretical frameworks underpinning research and clinical practice. 


\section{Limitations}

The establishment of reliable and robust methodologies for determining children's views remains a high priority area of research and development. In this study and more generally in conversations between children provided with communication aids and others, the accomplishment of an aided speaker's contribution involves explicit and active collaboration between both participants in interaction. Explicit negotiation of child meaning between the interviewer and the child may be viewed as weakening the credibility and authenticity of the views reported particularly if the interviewer is perceived to represent certain viewpoints. However, failing to collaborate in this way may introduce a potential risk of missing or misinterpreting children's actions, and limiting opportunities for children's self-expression. It is possible also that the veracity of findings may be diminished if interviewees choose to present themselves 'like other children' by falsely accepting as relevant to their own experience statements representing self-efficacy, self-esteem and others' attitudes. However, it is possible also that children may not have thought about, or been asked to consider, the issues under discussion, and that provision of other children's views provided a useful scaffold to children's decision making. The current study is relatively small in scale and scope. Close attention to the early stages of AAC introduction including assessment of multiple child and environmental outcomes, and factors underpinning those outcomes from the viewpoint of children themselves is clearly warranted. 


\section{References}

Beresford, B. (1997). Involving disabled children in research. Social Policy Research Unit.

Beresford, B., Tozer, R., Rabiee, P., \& Sloper, P. (2007). Desired outcomes for children and adolescents with autistic spectrum disorders. Children and Society, 21, 4-16.

Brewster, S. (2004). Putting words into their mouths? Interviewing people with learning disabilities and little/no speech. British Journal of Learning Disabilities., 32, 166-169.

Cavet, J. \& Sloper, P. (2004). Participation of disabled children in individual decisions about their lives and in public decisions about service development. Children and Society, 18, 278-290.

Clarke, M. T. (2002). Interviewing children and young people who use graphic symbol based augmentative and alternative communication (AAC) systems. In ESRC Seminar, Birmingham, October.

Clarke, M. T., McConachie, H. R., Price, K., \& Wood, P. (2001). Views of young people using augmentative and alternative communication systems. International Journal of Language and Communication Disorders, 36, 107-115.

Clarke, M. T., Newton, C., Griffiths, T., Price, K., Lysley, A., \& Petrides, K. V. (2011). Factors associated with the participation of children with complex communication needs. Research in Developmental Disabilities, 32, 774-780.

Dattilo, J., Estrella, G., Estrella, L., Light, J., McNaughton, D., \& Seabury, M. (2008). "I have chosen to live life abundantly": Perceptions of leisure by adults who use Augmentative and Alternative Communication. AAC: Augmentative and Alternative Communication, 24, 16-28.

Drager, K. D. R., Light, J. C., Speltz, J. C., Fallon, K. A., \& Jeffries, L. Z. (2003). The performance of typically developing 2 1/2-year-olds on dynamic display AAC technologies with different system layouts and language organizations. Journal of Speech, Language, and Hearing Research, 46, 298312.

Eriksson, L. \& Granlund, M. (2004). Conceptions of participation in students with disabilities and persons in their close environment. Journal of Developmental and Physical Disabilities, 16, 229245.

Fuhrer, M. J., Jutai, J. W., Scherer, M. J., \& DeRuyter, F. (2003). A framework for the conceptual modelling of assistive technology device outcomes. Disability and Rehabilitation, 25, 1243-1251.

Granlund, M., Bjorck-Akesson, E., Eriksson-Augustine, L., Pless, M., Simeonsson, R., Maxwell, G. et al. (2011). Differentiating activity and participation of children and youth with disability in Sweden - the need for a third qualifier in ICF-CY . American Journal of Physical Medicine and Rehabilitation.

Granlund, M., Bjorck-Akesson, E., Wilder, J., \& Ylven, R. (2008). AAC interventions for children in a family environment: Implementing evidence in practice. AAC: Augmentative and Alternative Communication, 24, 207-219.

Hodge, S. (2004). Why is the potential of augmentative and alternative communication not being realized? Exploring the experiences of people who use communication aids. Disability and Society, 22, 457-471. 
Hodge, S. (2007). Why is the potential of augmentative and alternative communication not being realized? Exploring the experiences of people who use communication aids. Disability and Society, $22,457-471$.

Iacono, T. (2003). The Evidence Base for Augmentative and Alternative Communication. In S.Reilly \& J. Oates (Eds.), In Evidence-Based Practice in Speech Pathology ( London: Wiley.

King, G., Law, M., Hurley, P., Petrenchik, T., \& Schwellnus, H. (2010). A developmental comparison of the out-of-school recreation and leisure activity participation of boys and girls with and without physical disabilities. International Journal of Disability, Development and Education, 57, 77-107.

Lenker, J. A. \& Paquet, V. L. (2003). A Review of Conceptual Models for Assistive Technology Outcomes Research and Practice. Assistive Technology, 15, 1-15.

Lewis, A. \& Porter, J. (2004). Interviewing children and young people with learning disabilities $†$ : guidelines for researchers and multi-professional practice. British Journal of Learning Disabilities., 32, 191-197.

Light, J. (1989). Toward a definition of communicative competence for individuals using augmentative and alternative communication systems. Augmentative and Alternative Communication, 5, 137-144.

Lund, S. \& Light, J. (2007). Long-term outcomes of individuals who use augmentative and alternative communication: Part II - Communication interaction. Augmentative and Alternative Communication, 23, 1-15.

Morris, J. (2003). Including All Children: Finding Out about the Experiences of Children with Communication and/or Cognitive Impairments. Children and Society, 17, 337-348.

Murphy, J., Gray, C. M., van Achterberg, T., Wyke, S., \& Cox, S. (2010). The effectiveness of the talking mats framework in helping people with dementia to express their views on well-being. Dementia, 9, 454-472.

Murray, J. \& Goldbart, J. (2009). Cognitive and language acquisition in typical and aided language learning: A review of recent evidence from an aided communication perspective. Child Language Teaching and Therapy, 25, 31-58.

Newton, C., Clarke, M. T., Donlan, C., Wright, J. A., Lister, C., \& Cherguit, J. (2007). Parents' expectations and perceptions concerning the provision of communication aids by the Communication Aids Project (CAP). Child Language Teaching and Therapy, 23, 47-65.

O'Keefe, B., Kozak, N. B., \& Schuller, R. (2007). Research priorities in augmentative and alternative communication as identified by people who use AAC and their facilitators. AAC: Augmentative and Alternative Communication, 23, 89-96.

Rabiee, P., Sloper, P., \& Beresford, B. (2005a). Desired outcomes for children and young people with complex health care needs, and children who do not use speech for communication. Health and Social Care in the Community, 13, 478-487.

Rabiee, P., Sloper, P., \& Beresford, B. (2005b). Doing research with children and young people who do not use speech for communication. Children and Society, 19, 385-396. 
Rackensperger, T., Krezman, C., McNaughton, D., Williams, M. B., \& D'Silva, K. (2005). "When I first got it, I wanted to throw it off a cliff": The challenges and benefits of learning AAC technologies as described by adults who use AAC. AAC: Augmentative and Alternative Communication, 21, 165-186.

Raghavendra, P., Bornman, J., Granlund, M., \& Bjorck-Akesson, E. (2007). The World Health Organization's International Classiffication of Functioning, Disability and Health: Implications for clinical and research practice in the field of augmentative and alternative communication. $A A C$ : Augmentative and Alternative Communication, 23, 349-361.

Smith, M. M. \& Connolly, I. (2008). Roles of aided communication: perspectives of adults who use AAC. Disability and rehabilitation.Assistive technology, 3, 260-273.

Weller, I. (2001). An investigation into the attitudes, expectations and the peer relationships of children and young people who use. BSc University College London.

Wickenden, M. (2010). Talking to Teenagers: Using Anthropological Methods to Explore Identity and the Lifeworlds of Disabled Young People Who Use AAC. Communication Disorders Quarterly, 20, 1-13.

Wickenden, M. Talk to me as a teenage girl: Experiences of friendship for disabled teenagers who have little or no speech. Childhoods Today, (in press).

World Health Org. (2001). International Classification of Functioning, Disability and Health. Geneva, World Health Organisation.

Ref Type: Generic

World Health Organisation (2001). International Classification of Functioning, Disability and Health. Geneva.: WHO.

World Health Organisation (2007). International Classification of Functioning, Disability and Health for Children and Youth (ICF-CY). Geneva: WHO.

Wright, J. A., Clarke, M. T., Donlon, C., Lister, C., Weatherly, H., Newton, C. et al. (2004). Evaluation of the communication aids project Final Report to the DfES. 
$\underline{\text { Table 1. Profile of children interviewed }}$

\begin{tabular}{|l|l|l|l|l|l|l|l|}
\hline Child & $\begin{array}{l}\text { Age at } \\
\text { Time1 }\end{array}$ & Sex & $\begin{array}{l}\text { Diagnosis/clinical } \\
\text { description }\end{array}$ & School & Aid & $\begin{array}{l}\text { Access } \\
\text { method }\end{array}$ & Weeks T1- T2 \\
\hline 1 & 7.06 & F & $\begin{array}{l}\text { Cerebral palsy } \\
\text { and global } \\
\text { developmental delay }\end{array}$ & Special & VOCA & D & 8 \\
\hline 2 & 7.10 & M & Trysomy 8 & Special \& M'stm & VOCA & D & 6 \\
\hline 3 & 10.01 & M & Cerebral Palsy & M'stm & VOCA & D & 6 \\
\hline 4 & 10.11 & M & $\begin{array}{l}\text { Worester Drought } \\
\text { Syndrome }\end{array}$ & Special & VOCA & D & 10 \\
\hline 5 & 11.07 & M & $\begin{array}{l}\text { Learning disabilities } \\
\text { and dyspraxia }\end{array}$ & Special & VOCA & D & 6 \\
\hline 6 & 12.03 & M & Cerebral Palsy & M'stm & VOCA \& Laptop & D & 6 \\
\hline 7 & 12.03 & F & Cerebral Palsy & Special & VOCA & D & 6 \\
\hline 8 & 14.02 & F & Cerebral Palsy & Special & VOCA & D & 6 \\
\hline 9 & 15.07 & M & Cerebral Palsy & Special & VOCA & InD & 6 \\
\hline 10 & 16.10 & M & Cerebral Palsy & M'stm & VOCA & InD & 10 \\
\hline
\end{tabular}

$\begin{array}{ll}\text { M'stm } & \text { Mainstream School } \\ \text { VOCA } & \text { Voice Output Communication Aid } \\ \text { D } & \text { Direct (finger, eye or light beam pointing) } \\ \text { InD } & \text { Indirect (switch or partner scanning) } \\ \text { Amb't } & \text { Ambulant }\end{array}$

Table 2: self-efficacy, self-esteem and other's attitudes issues

\begin{tabular}{|l|l|}
\hline Self-efficacy & $\begin{array}{l}\text { Issue } \\
\text { I have to rely on other people too much } \\
\text { Other people do it for me } \\
\text { It takes too long } \\
\text { It takes too much of effort }\end{array}$ \\
\hline Self-esteem & $\begin{array}{l}\text { It doesn't feel like my voice } \\
\text { I can't really be in control } \\
\text { I feel frustrated } \\
\text { I feel embarrassed / awkward }\end{array}$ \\
\hline Others' attitudes & $\begin{array}{l}\text { People treat me like a baby / younger person } \\
\text { People think I'm stupid }\end{array}$ \\
\hline
\end{tabular}




\begin{tabular}{|l|l|}
\hline & $\begin{array}{l}\text { People think I don't have anything interesting to say } \\
\text { I am not able to show the real me } \\
\text { Others think I can't help them }\end{array}$ \\
\hline
\end{tabular}

Table 3: Maya's views concerning the difficulty and importance of six activities

\begin{tabular}{|l|l|l|l|l|}
\hline Activity & $\begin{array}{l}\text { Difficulty at } \\
\text { T1 }\end{array}$ & Importance & $\begin{array}{l}\text { Expectations for } \\
\text { change in } \\
\text { difficulty }\end{array}$ & $\begin{array}{l}\text { Change in } \\
\text { difficulty at T2 }\end{array}$ \\
\hline Joking / teasing & Easy & Neutral & No change & Decrease \\
\hline $\begin{array}{l}\text { Answering } \\
\text { questions }\end{array}$ & Neutral & Important & No change & No change \\
\hline Asking questions & Neutral & Important & No change & Increase \\
\hline $\begin{array}{l}\text { Talking in front of } \\
\text { class }\end{array}$ & Neutral & Neutral & No change & No change \\
\hline $\begin{array}{l}\text { Telling news } \\
\text { Talking in groups }\end{array}$ & Difficult & $\begin{array}{l}\text { Not } \\
\text { important }\end{array}$ & No change & No change \\
\hline
\end{tabular}

Table 4: Maya's perceptions concerning changes in self-efficacy, self-esteem and others' attitudes.

\begin{tabular}{|l|c|c|}
\hline \multicolumn{2}{|c|}{$\begin{array}{c}\text { Degree to which issue } \\
\text { was problematic at } \\
\text { T1 }\end{array}$} & $\begin{array}{c}\text { Reported } \\
\text { change at T2 }\end{array}$ \\
\hline Self-efficacy & Neutral & No change \\
\hline I can't show what I can do & Small & No change \\
\hline I have to rely on others too much & Neutral & Decrease \\
\hline Others do it (talk) for me & Neutral & No change \\
\hline It takes too long & Big & No change \\
\hline It takes lots of effort & Big & No change \\
\hline Self-esteem & Big & No change \\
\hline I don't have a voice & Big & Decrease \\
\hline I am frustrated & Big & No change \\
\hline I feel embarrassed & Small & No change \\
\hline I don't have a voice & & \\
\hline Others don't know how I communicate & Big & Decrease \\
\hline Others' attitudes & Small & Decrease \\
\hline People think I'm stupid & & \\
\hline People think I don't have anything interesting to say & \multicolumn{2}{|c|}{} \\
\hline
\end{tabular}


Figure 1: Visual representation of school

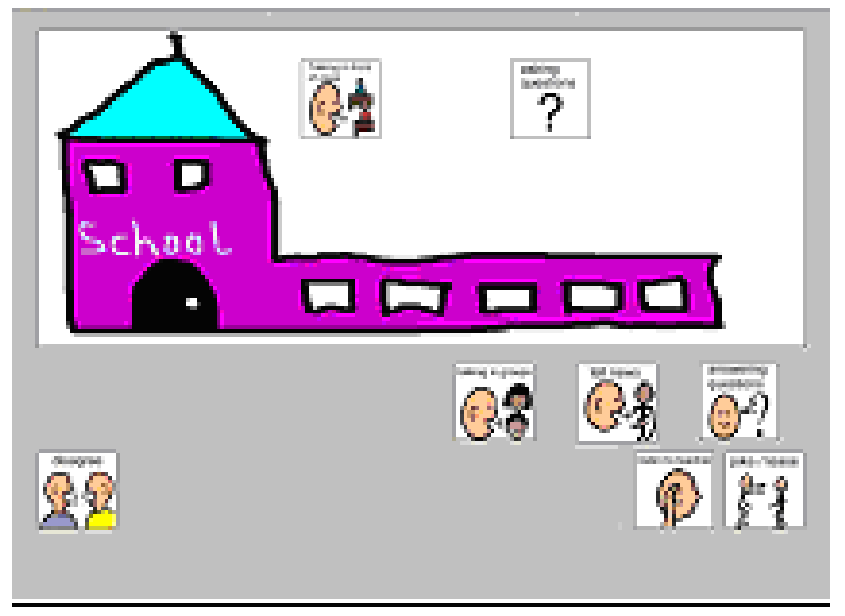

Figure 2: Illustration of visual display used in Stage 6

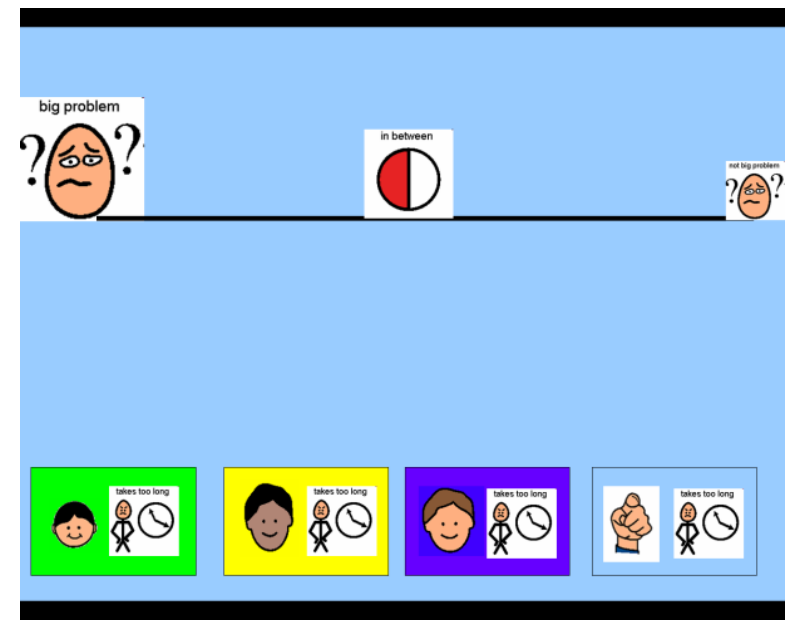

Figure 3: T1 predications and T2 perception of degree of difficulty in activities 


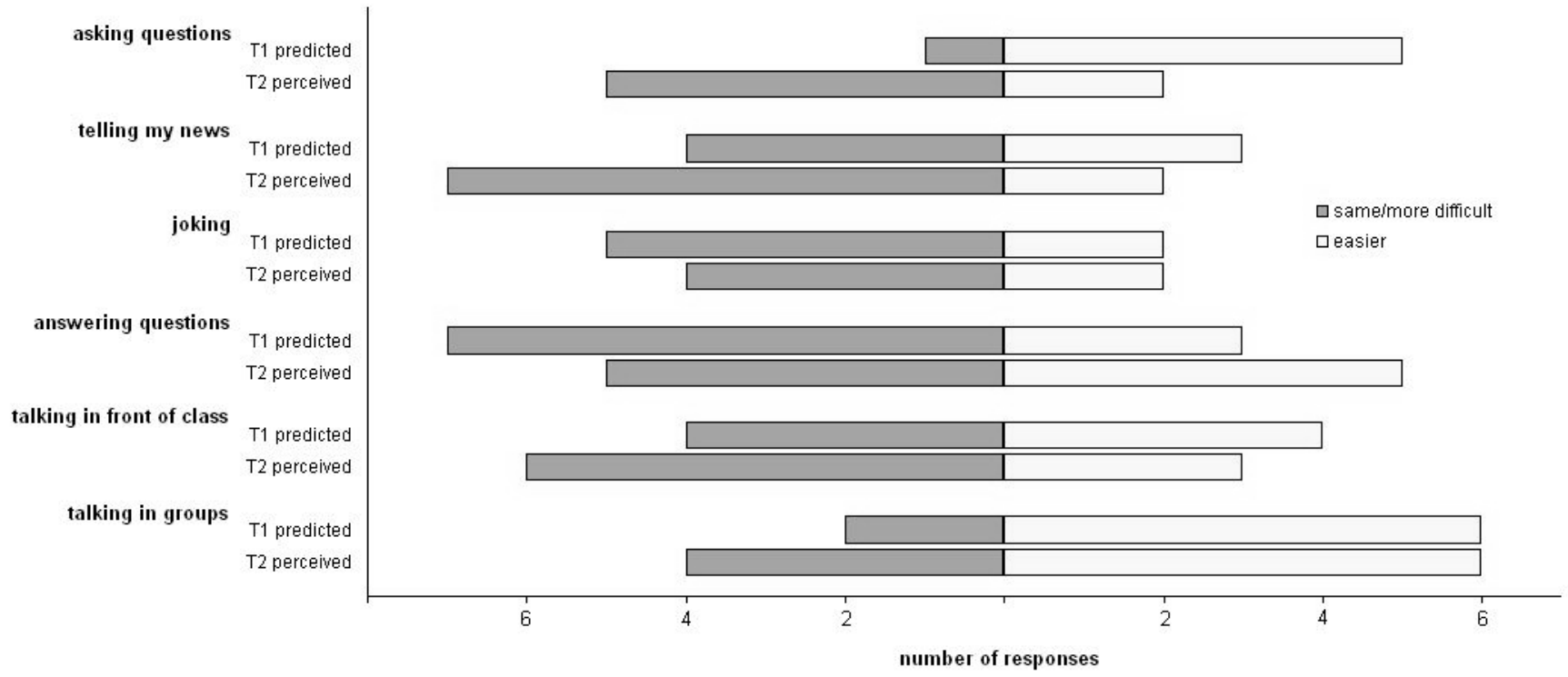

Figure 4. Changes in reported indicators of self-efficacy, self-esteem and others' attitudes

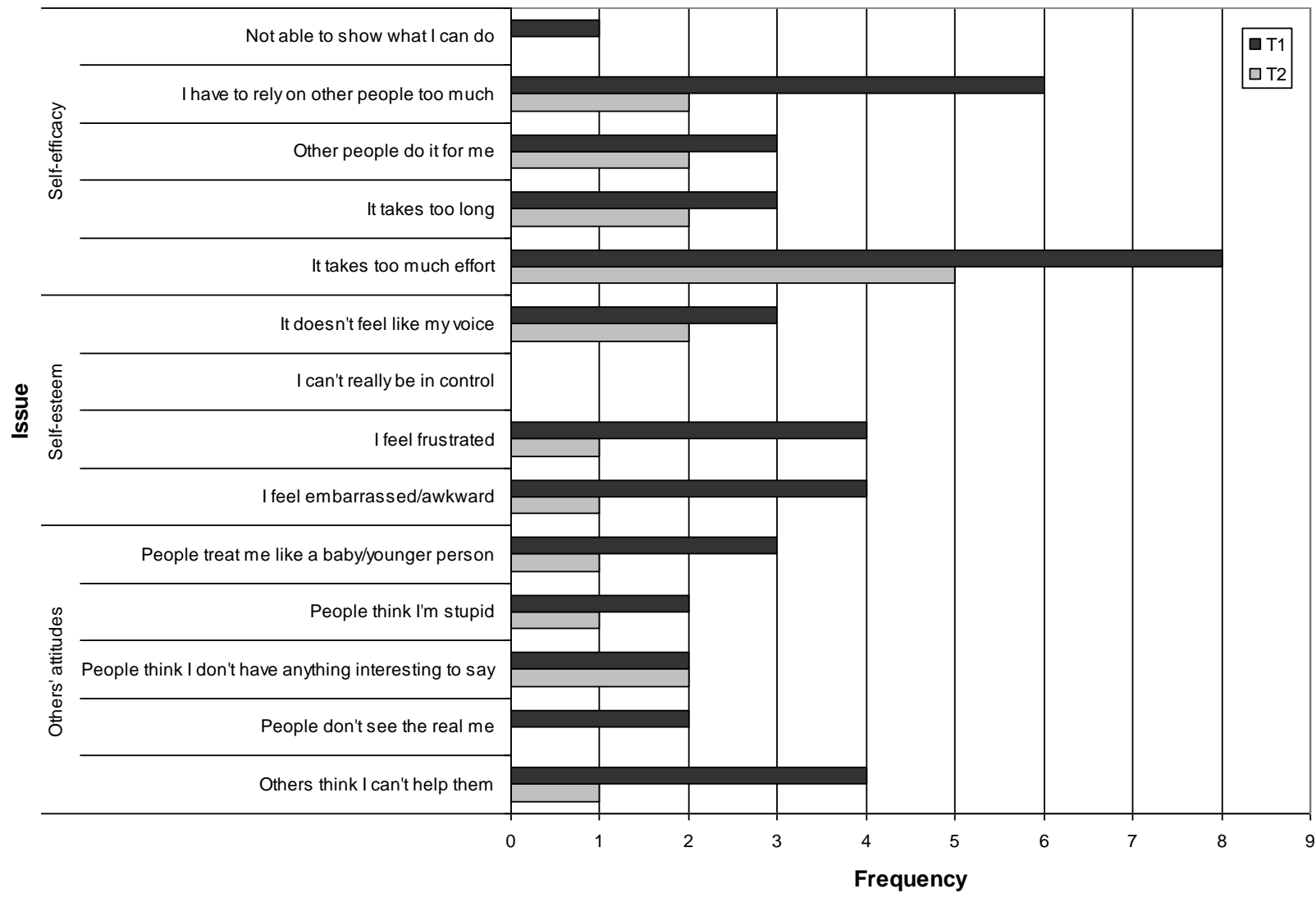

